\title{
Use of Transcutaneous Nervous Electrical Stimulation and Manual Therapy in Episodic Tension-Type Headache in Young Women
}

\author{
Cássio Brendon dos Santos ${ }^{1}$, Ellen Vitória Samuelsson Mussulini ${ }^{1}$, Jaqueline Trage ${ }^{1}$, Sérgio Mendes de Souza ${ }^{1}$, \\ José Luiz Marinho Portolez ${ }^{2}$, Alberito Rodrigo de Carvalho ${ }^{1}$ and Gladson Ricardo Flor Bertolini ${ }^{1 *}$
}

${ }^{1}$ Universidade Estadual do Oeste do Paraná (Unioeste), Cascavel Paraná, Brazil

${ }^{2}$ Universidade Santa Cecília (UniSanta), Santos São Paulo, Brazil

Submission: March 07, 2019; Published: June 06, 2019

*Corresponding author: Gladson Ricardo Flor Bertolini, Universidade Santa Cecília (UniSanta), Santos São Paulo, Brazil

\begin{abstract}
An episodic tension-type headache (ETH) is a headache that affects a large percentage of the world's population. The objective of this study was to compare the effects of the high-frequency transcutaneous electrical nerve stimulation (TENS) and the manual therapy protocol on the intensity of pain and reported headache's episodes of patients with ETH. The sample was composed of 28 women with ETH and ages ranging from 18 to 35 years. The subjects were randomly divided into four groups (n=7 in each): Control Group (GC), Manual Therapy Group (GTM), TENS Group (GTENS) and Manual Therapy Group + TENS (GTM + TENS). Before the treatment, patients underwent a specific evaluation for ETH based on International Society of Headache diagnostic criteria, and this assessment was repeated at the end of treatment. The evaluation of the frequency of headache's episodes and their comorbidities was performed weekly, once in each of the four weeks of intervention (EV1, EV2, EV3, and EV4), by a symptom reporting. For the evaluation of pain intensity in the period before and after the interventions, the Visual Analog Pain Scale (VAS) was used. The Interventions occurred twice a week for one month. Based on the results, it was observed that all the techniques were effective to decrease pain intensity and to reduce the frequency of headache cases during the treatment period, but statistically, it was not possible to discriminate the best technique for the treatment of the ETH.
\end{abstract}

Keywords: Tensyon-type headache; Electric stimulation therapy; Musculoskeletal manipulations

Abbreviations: ETH: episodic tension-type headache; GC: Control Group; GTM: Manual Therapy Group; GTENS: TENS Group; GTM + TENS: Manual Therapy Group + TENS; TENS: transcutaneous electric nerve stimulation; VAS: Visual Analog Pain Scale.

\section{Introduction}

Chronic daily headache is a dysfunction that affects 2 to $4 \%$ of the North American and European population [1]. A tension headache generates effects on social activities and working capacity of those who suffer it [2]. Their incidence in Australian population is about $40 \%$, being estimated prevalence between 40 to $46 \%[3,4]$. According to the third edition of the classification criteria of the International Society of Headaches (IHS), there are five main primary types of a headache: a migraine without or with aura, episodic tension-type headache, chronic and salivary. An episodic tension-type headache (ETH) can be divided into three subtypes according to their frequency: [1] infrequent ETH ( $<12$ days of headache/year), [2] frequent ETH (12-180 days of headache/year) and [3] chronic ETH (> 180 days of headache/ year). The diagnostic criteria for ETH require at least two of the following characteristics: bilateral location, character in pressure/tightness (non-pulsatile), weak to moderate intensity, not aggravated by routine physical activities such as walking or climbing stairs [5].
The treatment for ETH is usually pharmacological, with a high risk of medication overuse [6], a manifestation of the side effects, and the lack of response to the therapy adopted. One of the treatment possibilities for this disease is the physiotherapy. This therapeutic modality uses various techniques such as electrotherapy, acupuncture, cervical traction, kinesiotherapy and vertebral mobilizations [7]. Considering electrotherapy techniques, one of the most used is transcutaneous electrical nerve stimulation (TENS). TENS is a non-invasive technique in which low-frequency currents are used on the skin, which provides relief from acute and chronic pain [8-10]. About TENS' mechanisms of pain relief, high frequencies perform analgesia according to gate-control theory, in which it is necessary that large afferent fibers be activated, producing the so-called ascending analgesia [10]. Manual therapy, in turn, aims among other actions to induce muscle relaxation by stimulating the Golgi tendon organs, to induce direct stimulation of the mechanoreceptors, to release of endogenous opioids, to increase 
local circulation and to remove metabolites that produce pain [7]. Despite indications of good results with both therapies, there is a gap in the comparison of these modalities. In this context, the objective of the present study was to compare the effects of the high-frequency TENS and the manual therapy protocol on the intensity of pain and reported headache's episodes of patients with ETH.

\section{Materials and Methods}

This research is a cross-sectional study with an interventionist approach, and it was developed at the Physical Rehabilitation Center of the State University of the West of Paraná - UNIOESTE. The participants were recruited for convenience among university students with characteristics of the ETH, according to the International Headache Society [5]. and all of them signed the Informed Consent Form for research (approved by the Research Ethics Committee of the Unioeste, under number report 2.162.833). The inclusion criteria were: women aged between 18 and 35 years, diagnosed with episodic tension-type headache and who were not performing another form of treatment. Exclusion criteria were another headache type, cardiopathies, oncological diseases or pregnancy.

We selected 28 female subjects, with an average age of $21.3 \pm 3.2$ years, the height of $1.64 \pm 0.1 \mathrm{~m}$, the weight of 59.8 $\pm 14.3 \mathrm{~kg}$ and the body mass index of $22.2 \pm 5.3 \mathrm{~kg} / \mathrm{m}^{2}$. They were allocated, by a lot, in four groups: Control Group (GC), Manual Therapy Group (GTM), TENS Group (GTENS) and Manual Therapy Group + TENS (GTM + TENS). The intervention period consisted of eight treatment sessions, twice on the week for four weeks.

For the evaluation of pain intensity in the period before and after the interventions, the Visual Analog Pain Scale (VAS) was used with a scale from zero means the absence of pain to ten means maximum pain experienced. The evaluation of the frequency of headache's episodes and their comorbidities was performed weekly, once in each of the four weeks of intervention (EV1, EV2, EV3, and EV4), by a symptom reporting [11]. Data reported were about:

i. the time the pain was felt, if uni or bilateral.

ii. the occurrence of side effects such as nausea, vertigo, and vomiting.

iii. occurrence or not of the menstrual period.

The Manual Therapy treatment protocol consisted of the application of three techniques, aiming at the relaxation of the suboccipital musculature:

i. Inhibition of suboccipital muscles: The therapist made contact with the pulp of the index, middle and ring fingers in the suboccipital muscles of the patient, in which the patient presented tension and, due to the position in which it was, maintained a small cervical flexion. As occurred with muscle inhibition, the occurrence of the cervical extension was automatically noticed.

ii. Suboccipital Stretching: One of the therapist's hands made contact with the occipital region while the other was located on the forehead. A flexion associated with traction was then performed.

iii. Stretching of head extensors: In this maneuver the therapist crossed arms under the suboccipital region of the patient, taking manual contact on his shoulders. The sternum of the therapist remained in contact with the patient's head in order to feel the tension generated with the movement of passive cervical flexion.

The TENS application occurred as follows: the equipment was adjusted in the continuous mode, at the frequency of 100 $\mathrm{Hz}$, with phase duration of $250 \mu$ s, for 20 minutes. Previously, we did the asepsis of the area to be treated using $70 \%$ alcohol. The gel was distributed on the surface of the rubber-silicone electrode $(2 \times 4 \mathrm{~cm})$, to avoid direct contact of the electrode on the patient's skin. One electrode was fixed at the spinous process of the third cervical vertebra (C3) and the other in the spinous process of the seventh cervical vertebra (C7). After this procedure, the current intensity was increased until the patient felt a "tingling" sensation. The patient reported their sensations so that the therapist could avoid accommodation of the current. The data were presented in medians and quartiles and were analyzed using the Kruskal-Wallis test with Student-NewmanKeuls post-test, in the comparisons between groups. In the intragroup comparison, Wilcoxon was used in all cases the accepted level of significance was $5 \%$. The Biostat 5.0 program was used.

\section{Results}

Table 1: Presentation of pain VAS results at the beginning and the end of treatment.

\begin{tabular}{|c|c|c|c|}
\hline \multirow{2}{*}{ GC } & Start & End & \multirow{2}{*}{ P-value } \\
\hline \multirow{2}{*}{ GTM } & $7 \mathrm{a}$ & $6 \mathrm{a}$ & \multirow{2}{*}{0,3575} \\
\cline { 2 - 3 } & $5,5-7,5$ & $6-7$ & \\
\cline { 2 - 3 } & $7 \mathrm{a}$ & $3 \mathrm{~b}$ & \multirow{2}{*}{0,0213} \\
\hline \multirow{2}{*}{ GTENS } & $6,5-8$ & $1,5-3,5$ & \multirow{2}{*}{0,0090} \\
\cline { 2 - 3 } & $7 \mathrm{a}$ & $2 \mathrm{~b}$ & \multirow{2}{*}{0,0090} \\
\hline \multirow{2}{*}{ GTM+TENS } & $7 \mathrm{a}$ & $1-3$ & \\
\cline { 2 - 3 } & $6,5-8$ & $0-2$ & \multicolumn{2}{|c}{} \\
\hline \multirow{2}{*}{ p-value } & 0,5681 & 0,0018 & \\
\hline
\end{tabular}

Equal letters demonstrate statistical similarities within and between groups.

In percentage terms, $89 \%$ of subjects reported emotional stress as the main cause of headache. The patients presented muscle tension points in the suboccipital and temporomandibular region. Tension points were also found in the upper trapezius, scalenes (anterior, middle and posterior), sternocleidomastoid and pectoralis major muscles in all participants, and these 
tensions were decreased or absent at the end of the intervention. For intensity of pain, the intra-group comparison showed significant differences at the three groups treated, but not for the control group. In the comparison between the groups in AV1 there were no significant differences, but in AV2, all treated groups were different from the control, with no differences between them (Table 1). By the symptom reporting data, we obtained the frequency of headache episodes experienced by the patients. This data was evaluated weekly between the subjects and at the end of four weeks between the different groups (Table 2). The results suggest that only in the GTM statistically significant differences were found $(p=0.0183)$. To find where these differences occurred the Student-Newman Keuls post-test was used, which showed differences in the analyzes between the 1st and 3rd weeks ( $p=0,0457), 2$ nd and 3rd weeks ( $p=0,0118$ ) and 2 nd and 4 th weeks ( $\mathrm{p}=0.022)$.

Table 2: Statistical analysis of the results obtained by the Diary of Headache.

\begin{tabular}{|c|c|c|c|c|c|}
\hline & EV1 & EV2 & EV3 & EV4 & P-value \\
\hline \multirow{2}{*}{ GC } & $4 \mathrm{aA}$ & $3 \mathrm{aA}$ & $4 \mathrm{aA}$ & $4 \mathrm{aA}$ & \multirow{2}{*}{0,1474} \\
\cline { 2 - 5 } & $3,5-4,5$ & $3-3$ & $2,5-4$ & $3-4,5$ & \\
\hline \multirow{2}{*}{ GTM } & $3 \mathrm{acA}$ & $3 \mathrm{aA}$ & $1 \mathrm{bA}$ & $2 \mathrm{bcB}$ & \multirow{2}{*}{0,0183} \\
\cline { 2 - 5 } & $2,5-3$ & $2,5-4,5$ & $1-2$ & $1-2$ & \\
\hline \multirow{2}{*}{ GTENS } & $2 \mathrm{aA}$ & $2 \mathrm{aB}$ & $2 \mathrm{aA}$ & $1 \mathrm{aB}$ & \multirow{2}{*}{0,2222} \\
\cline { 2 - 5 } & $2-3,5$ & $1,5-2$ & $1-3$ & $0-1,5$ & \\
\hline \multirow{2}{*}{ GTM+TENS } & $3 \mathrm{aA}$ & $3 \mathrm{aA}$ & $1 \mathrm{aA}$ & $1 \mathrm{aB}$ & \multirow{2}{*}{0,0531} \\
\cline { 2 - 5 } & $1,5-3$ & $1,5-3$ & $0-1,5$ & $0-1,5$ & \\
\hline p-value & 0,1939 & 0,0477 & 0,1027 & 0,0031 & \\
\hline
\end{tabular}

Equal letters have statistical similarity. Lowercase letters compare intragroup and uppercase between groups.

\section{Discussion}

A headache is one of the most common symptoms found in the human species [11]. Among the various headache's types, the tension headache is highlighted, for which there is evidence of the need for holistic therapies and should not be restricted to drug therapy alone [4]. Thus, in the present study, we opted to compare two forms of physiotherapeutic treatment, as well as the association of the techniques. These were able to reduce the intensity of pain as well as the number of associated symptoms. Several theories are proposed for the analgesic effect of electrostimulation in cases of a headache. The gate theory suggests that a stimulation of large diameter sensory afferents, such as the major occipital nerve, could produce analgesia due to pre-synaptic inhibition of small diameter nociceptive fibers. Another possible explanation is an increase in regional cerebral blood flow, suggesting central neuromodulation. It is still known that during headache's episodes there is an increase in peptide levels related to the calcitonin gene (CGRP), so a blockade of its receptors could cause analgesia. Another possible mechanism is the stimulation of the descending pathway of pain control by serotonin release by the pain matrix [3].
Bono et al. [12] performed the use of TENS with biphasic current, $250 \mu \mathrm{s}$, but with fixed intensity at $20 \mathrm{~mA}$ and $40 \mathrm{~Hz}$, in ETH patients three times a day for two weeks in the occipital region. They observed a reduction in the number of days per month of a headache in individuals who did not have allodynia, indicating that the therapeutic response is associated with the severity of the patient's pain. Lindelof et al. [13] evaluated the pain response in 20 patients with ETH exposed to 20 minutes of low-frequency electrical stimulation (1 HZ). They observed a decrease in pain response to electrical stimulation of up to one hour after electrostimulation. Mousavi et al. [14] observed preventive analgesic effects for TENS in patients with ETH treated three times per week for ten weeks, 15 minutes per session in the temporal and occipital regions, with a reduction in headache severity. These findings corroborate those found in the present study since the use of TENS produced a reduction in pain intensity, as well as a reduction in the symptoms observed in the symptom reporting data when compared to the control group.

According to Caballero-Calixto et al. [15], manual therapy is an effective alternative in reducing painful symptoms in patients with ETH, and there are several approaches, such as joint techniques, soft tissue mobilization, and muscle training. However, the heterogeneity of the patients' symptoms does not allow for standardizing a protocol of treatment with a specific technique. Thus, the best results are associated with the use of the two or more manual techniques. Not only is it important to reduce the pain intensity, but also the frequency of pain. Although the etiological cause of ETH is uncertain, the frequent association of symptoms associated with a headache, such as trigger points in the cervical and pericranial zone, the rigidity of the cervical vertebral structures and inhibition of the stabilizing musculature, motivates the development of a therapy manual treatment that addresses each of the dysfunctional characteristics of the ETH. Thus, in the present study, four manual therapy techniques were chosen, and their association produced a reduction in pain intensity, and in the frequency of the symptoms.

Manual therapy may improve symptoms of ETH by mobilizing the spine, correcting posture, and training cervical muscles [6]. But according to Fernández-de-las-Peñas et al. [16], despite a high demand of individuals with ETH for the use of such therapies, the evidence in the literature about this therapy modality is still very poor, and there is little research, generally of poor methodological quality, and thus more clinical trials are needed. This last affirmation is corroborated by Moore, Sibbritt, \& Adams [17], who still mention the importance of evaluating the association of therapies. In the present study, the association of manual therapy with TENS produced analgesic effects. However, it was not superior to any of the isolated modalities.

Most of the patients presented bilateral ETH, which is in agreement with the data of Varjão et al. [18], according to this 
authors, a bilateral headache is a characteristic present in $90 \%$ of the patients, with localized pain usually in the occipital, parietal and frontal regions, maintaining a mild to moderate intensity. Considering the triggers of headache in this study, it was observed that almost all of the participants reported stress as an aggravating factor for these pains, which is in agreement with the literature regarding work satisfaction as an ETH inductor [19], including one of the forms of treatment used is psychotherapy aimed at reducing stress $[20,21]$. In the study, the two techniques (TENS and TM) showed significant results $(p<5 \%)$ when compared with the control group, both in the frequency of the episodes and in the intensity of pain. When comparing the intervention groups with each other, the tests showed no significant differences, indicating that none of the techniques alone or in combination excelled the other forms. The search for alternative forms for a tension headache is still not very frequent, because many patients with this disorder are unaware of the existence of other therapeutics [18]. In this study, the participants reported that they had never sought conservative treatment for headache relief and that whenever symptoms appeared, they self-medicated or waited for the pain to disappear without taking any action. An important aspect to be considered is the need for studies evaluating the therapies in the medium and long-term, mainly verifying that in the posttreatment period, there is direct interference in the quality of life of the patients, since this disease, besides presenting a high prevalence and significantly affects activities of daily living, such as academic life [22].

\section{Conclusion}

The use of physical therapy through continuous TENS, Manual Therapy and TENS combined with Manual Therapy may contribute to the improvement of a tension headache.

\section{References}

1. Sheeler RD, Garza I, Vargas BB, Neil AE (2016) Chronic daily headache: ten steps for primary care providers to regain control. Headache 56(10): 1675-1684.

2. Da Cunha Matta AP, Moreira Filho PF (2006) Cefaléia do tipo tensional episódica: Avaliação clínica de 50 pacientes. Arq Neuropsiquiatr 64(1):95-99.

3. Lee P, Huh BK (2013) Peripheral nerve stimulation for the treatment of primary headache. Curr Pain Headache rep. 17(3): 319.

4. Wool house M (2005) Migraine and tension headache. A complementary and alternative medicine approach. Aust Fam Physician 34(8): 647-651.

5. Olesen J, Bendtsen L, Dodick D, Ducros A, Evers S, First M, et al. (2018) Headache Classification Committee of the International Headache Society (IHS). The International Classification of Headache Disorders, 3rd edition. Cephalalgia 38(1): 1-211.

6. Castien RF, Van Der Windt DA, Dekker J, Mutsaers B, Grooten A (2009) Effectiveness of manual therapy compared to usual care by the general practitioner for chronic tension-type headache: Design of a randomised clinical trial. BMC Musculoskelet Disord. 10(21).
7. Morelli JG, Rebelatto JR (2007) The effectiveness of manual therapy in individuals with headaches, with and without cervical degeneration: analysis of six cases. Rev Bras Fisioter 11(3): 285-289.

8. Liebano R, Rakel B, Vance CGT, Walsh DM, Sluka KA (2011) An Investigation of the development of analgesic tolerance to transcutaneous electrical nerve stimulation (TENS) in humans. Pain 152(2): 335-342.

9. Moran F, Leonard T, Hawthorne S, Hughes CM, McCrum-Gardner E, et al. (2011) Hypoalgesia in response to transcutaneous electrical nerve stimulation (TENS) depends on stimulation intensity. J Pain 12(8): 929-235.

10. Vance GT, Dailey DL, Rakel BA, Sluka KA (2014) Using TENS for pain control: the state of the evidence. Pain Manag 4(3): 197-209.

11. Arruda MA (2009) Enxaqueca na infância e adolescência: atualização no diagnóstico e tratamento. Pediatr Mod 45(2): 37-50.

12. Bono F, Salvino D, Mazza MR, Curcio M, Trimboli M, et al. (2015) The influence of ictal cutaneous allodynia on the response to occipital transcutaneous electrical stimulation in chronic migraine and chronic tension-type headache: A randomized, sham-controlled study. Cephalalgia 35(5): 389-398.

13. Lindelof K, Jung K, Ellrich J, Jensen R, Bendtsen L (2010) Low-frequency electrical stimulation induces long-term depression in patients with chronic tension-type headache. Cephalalgia 30(7): 860-867.

14. Mousavi SA, Mirbod SM, Khorvash F (2011) Comparison between efficacy of imipramine and transcutaneous electrical nerve stimulation in the prophylaxis of chronic tension-type headache: a randomized controlled clinical trial. J Res Med Sci 16(7): 923-927.

15. Caballero CL, Antón-Puescas P, Reyna-Ormeño J (2017) Effect of manual therapy on tension headache. Neurology. 33(3): 201-202.

16. Fernándes-de-las-Peñas C, Alonso-Blanco C, San-Román J, Miangolarra-Page JC (2006) Methodological quality of randomized controlled trials of spinal manipulation and mobilization in tension-type headache, migraine, and cervicogenic headache. J Orthop Sport Phys Ther 36(3): 160-169.

17. Moore CS, Sibbritt DW, Adams J (2017) A critical review of manual therapy uses for headache disorders: prevalence, profiles, motivations, communication and self-reported effectiveness BMC Neurol 17(1): 61.

18. Varjão FM, Jorge JH, Nepelenbrock KH, Alencar (2008) de. Cefaleia do tipo tensional. Rev Saúde e Pesqui 1(2): 185-191.

19. Mahdavi A, Nikmanesh E, Aghael M, Kamran F, Tavakoli ZZ, et al. (2015) Predicting the level of job satisfaction based on hardiness and its components among nurses with tension headache. J Med Life 8(4): 93-96.

20. Omidi A, Zargar F (2014) Effect of mindfulness-based stress reduction on pain severity and mindful awareness in patients with tension headache: a randomized controlled clinical trial. Nurs Midwifery Stud 3(3): e21136.

21. Omidi A, Zargar F (2015) Effects of mindfulness-based stress reduction on perceived stress and psychological health in patients with tension headache. J Res Med Sci 20(11): 1058-1063.

22. Lima AS, Araújo RC de, Gomes MR de A, Almeida LR de, Souza GFF de, et al. (2014) Prevalence of headache and its interference in the activities of daily living in female adolescent students. Rev Paul Pediatr 32(2): 256-261. 
This work is licensed under Creative Commons Attribution 4.0 License DOI: 10.19080/JYP.2019.07.555714
Your next submission with Juniper Publishers will reach you the below assets

- Quality Editorial service

- Swift Peer Review

- Reprints availability

- E-prints Service

- Manuscript Podcast for convenient understanding

- Global attainment for your research

- Manuscript accessibility in different formats

( Pdf, E-pub, Full Text, Audio)

- Unceasing customer service

Track the below URL for one-step submission

https://juniperpublishers.com/online-submission.php 